\title{
WAYS OF OPTIMIZING THE DIAGNOSTICS OF FOOD ALLERGIES IN CHILDREN BASED ON THE CLINICAL AND IMMUNOLOGICAL CRITERIA
}

10.36740/WLek202010129

\author{
Tetyana 0. Kryuchko , Liudmyla M. Bubyr, Inna M. Nesina, Olha Y. Tkachenko, Olga V. Izmailova, Olha A. Poda, \\ Viktoriia V. Shcherbak \\ UKRAINIAN MEDICAL STOMATOLOGICAL ACADEMY, POLTAVA, UKRAINE
}

\begin{abstract}
The aim of the research was to investigate the spectrum of food sensitization, followed by the determination of the main clinical criteria and immunological markers of food allergy in children with gastroduodenal pathology and atopic dermatitis.

Materials and methods: We conducted a comprehensive clinical and immunological examination of 120 children aged from 6 to 15 years with gastroduodenal pathology (group $1 ; n=64$ ) and atopic dermatitis (group 2; $n=56$ ), who had a history of adverse allergic reactions to food. The control group consisted of 22 apparently healthy children. Results: In the group of children with gastroduodenal pathology, the spectrum of the most common significant food allergens was represented by legumes, the reaction to which was observed in $25(39.1 \%)$ subjects, eggs (25.0\%) and fish (23.4\%), which were found in every fourth child. Among patients with atopic dermatitis, the leading positions were occupied by fruits, which were registered in 20 (35.7\%) children, nuts - in $15(26.8 \%)$, honey and vegetables - in 11 (19.6\%) children, respectively. The study of immunological status in comparison with the control group revealed reliable increases in pro-inflammatory T-helper-2 cytokines - interleukin-4 and chemokine TARC/CCL-17 and a simultaneous decrease in anti-inflammatory interleukin-10 in children of the 1st and 2nd groups who had gastrointestinal and skin manifestations of allergic reactions when eating food products.

Conclusions: The study of peculiarities of adverse reactions to food in the examined children allowed us to identify specific clinical criteria and immunological markers of food allergy, which had certain features depending on the skin or gastrointestinal manifestations.
\end{abstract}

KEY WORDS: food allergy, children, diagnosis, allergens, immunological markers

Wiad Lek. 2020;73(10):2255-2260

\section{INTRODUCTION}

At the present stage in Ukraine and the world medical space, there is no high-quality evidence of the exact prevalence of food allergy (FA), which is due to the difficulty of conducting the oral provocation test as a "gold» standard of diagnostics. However, according to numerous studies by scientists based on questionnaires, skin allergy testing and determination of specific immunoglobulins E, one can observe a steady increase in the prevalence of food allergies in both Western and developing regions [1]. Thus, today, the World Health Organization has recognized FA as the «second wave» of the allergy epidemic after bronchial asthma [2]. Despite the widespread prevalence of food allergies and large-scale studies among European and American experts in this field, there are currently no clear unified approaches to the diagnosis of food allergies, which significantly inhibits the timely detection of pathology and early implementation of elimination measures. Therefore, the medical community needs to implement recommendations for the management of food allergies, taking into account epidemiological and age aspects for further development of preventive strategies that will reduce the spread of this pathology.

\section{THE AIM}

Given the urgency of this issue and the need to optimize the diagnostic algorithm, the aim of the investigation was to study the spectrum of food sensitization, followed by the determination of the main clinical criteria and immunological markers of food allergy in children with gastroduodenal pathology and atopic dermatitis.

\section{MATERIALS AND METHODS}

To achieve this aim, we conducted a comprehensive clinical and immunological examination of 120 children aged from 6 to 15 years with gastroduodenal pathology (group 1; $\mathrm{n}=64$ ) and atopic dermatitis (group 2; $\mathrm{n}=56$ ), who had a history of adverse allergic reactions when consuming food products. The control group consisted of 22 apparently healthy children stratified by age and gender according to the main groups. The study included children who were examined and treated at the Regional Children's Clinical Hospital of Poltava at pediatric departments of allergology and gastroenterology only with the informed consent of parents. Immunological studies were performed in 
Table 1. Comparative evaluation of the spectrum of sensitization to food allergens in the observation groups

\begin{tabular}{|c|c|c|c|c|c|}
\hline & $\begin{array}{c}\text { Group } 1 \\
\begin{array}{c}\text { Children with gastroduodenal } \\
\text { pathology }(n=64)\end{array}\end{array}$ & $\begin{array}{c}\text { Group } 2 \\
\text { Children with atopic } \\
\text { dermatitis }(n=56)\end{array}$ & $\begin{array}{c}X^{2} \\
d f=1\end{array}$ & $\begin{array}{c}\text { OR } \\
(95 \% \mathrm{Cl})\end{array}$ & $\mathbf{p}$ \\
\hline & abs. (\%) & abs. (\%) & & & \\
\hline Legumes & $25(39.1)^{*}$ & $10(17.9)$ & 5.51 & $\begin{array}{c}2.95 \\
(1.24-6.59)\end{array}$ & 0.019 \\
\hline Grains & $3(4.7)$ & $10(17.9)^{*}$ & 4.09 & $\begin{array}{c}0.23 \\
(0.07-0.90)\end{array}$ & 0.043 \\
\hline Fish and seafood & $15(23.4)$ & $7(12.5)$ & 1.71 & $\begin{array}{c}2.14 \\
(0.79-5.38) \\
\end{array}$ & 0.191 \\
\hline Dairy products & $5(7.8)$ & $3(5.4)$ & 0.03 & $\begin{array}{c}1.50 \\
(0.35-5.67)\end{array}$ & 0.864 \\
\hline Eggs & $16(25.0)^{*}$ & $5(8.9)$ & 4.29 & $\begin{array}{c}3.40 \\
(1.12-9.03) \\
\end{array}$ & 0.038 \\
\hline Meat & $4(6.3)$ & $1(1.8)$ & 0.58 & $\begin{array}{c}3.67 \\
(0.42-18.10) \\
\end{array}$ & 0.445 \\
\hline Nuts & $8(12.5)$ & $15(26.8)$ & 3.07 & $\begin{array}{c}0.39 \\
(0.16-1.02)\end{array}$ & 0.080 \\
\hline Vegetable & $10(15.6)$ & $11(19.6)$ & 0.11 & $\begin{array}{c}0.76 \\
(0.30-1.92)\end{array}$ & 0.736 \\
\hline Fruits & $14(21.9)$ & $20(35.7)$ & 2.18 & $\begin{array}{c}0.50 \\
(0.23-1.13) \\
\end{array}$ & 0.140 \\
\hline Seeds and spices (sesame, etc.) & $6(9.3)$ & $2(3.6)$ & 0.82 & $\begin{array}{c}2.79 \\
(0.54-10.91) \\
\end{array}$ & 0.366 \\
\hline Chocolate & $6(9.3)$ & $8(14.3)$ & 0.30 & $\begin{array}{c}0.62 \\
(0.21-1.89)\end{array}$ & 0.582 \\
\hline Honey & $5(7.8)$ & $11(19.6)$ & 2.67 & $\begin{array}{c}0.35 \\
(0.12-1.08)\end{array}$ & 0.103 \\
\hline
\end{tabular}

Note. ${ }^{*}$ - the significance of the difference as opposed to the indicators of the comparison group $(p<0.05)$

patients with a precise history of allergies associated with the intake of a particular food product when the standard allergological examination (skin testing and determination of general and specific immunoglobulin $\mathrm{E}$ ( IgE)) coincided with clinical data.

Clinically significant characteristics of food allergy are dose dependence, regular occurrence of reactions after ingestion of the causative product and reversibility of clinical manifestations with the exclusion of the suspected component from the diet. Therefore, in order to gradually assess the clinical symptoms, determine the spectrum of food sensitization, to study the frequency and rate of reaction after consumption of the suspected product, patients were surveyed using the "AllergoScope" questionnaire. The next step was to study the cytokine profile to determine the level of interleukins 4 (IL-4), 10 (IL-10) and thymus, as well as activation of the regulated chemokine TARC/CCL-17 in order to clarify the role of immunologically mediated mechanisms in the development of allergic reactions when eating certain food ingredients. The results of the study were analyzed on a personal computer using the Windows 7.0 operating system and the "Statistica 6.0" software (StatSoft Inc., USA, №AXXR712D833214FAN5).

\section{RESULTS AND DISCUSSION}

In the course of a careful analysis of the questionnaire data, we identified the most common etiologically significant allergens in children with gastroduodenal pathology and atopic dermatitis, who had a history of food allergies (Table 1). Hence, in the first group of observations, the spectrum of the most common significant food allergens was represented by legumes, the reaction to which was observed in $25(39.1 \%)$ subjects, eggs (16 (25.0\%)) and fish $(15(23.4 \%)$ ), which were found in every fourth child. In the group of children with atopic dermatitis, the leading positions were occupied by fruits 20 (35.7\%), nuts 15 (26.8\%), honey and vegetables, which were found in 11 (19.6\%) children, respectively.

It should be noted that the frequency of allergic reactions when eating peanuts and other products from the legume family was reliably by 2.2 times higher than in the group of children with atopic dermatitis $\left(\chi^{2}=5.51\right.$; $\mathrm{OR}=2.95$; $\mathrm{CI}=1.24-6.59 ; \mathrm{p}=0.019$ ).

Superficial non-detailed assessment of the nutritional history in patients with food allergies does not provide a high degree of probability to investigate the characteristic pathognomonic criteria of food intolerance. In addition, the availability of information on the development of ad- 

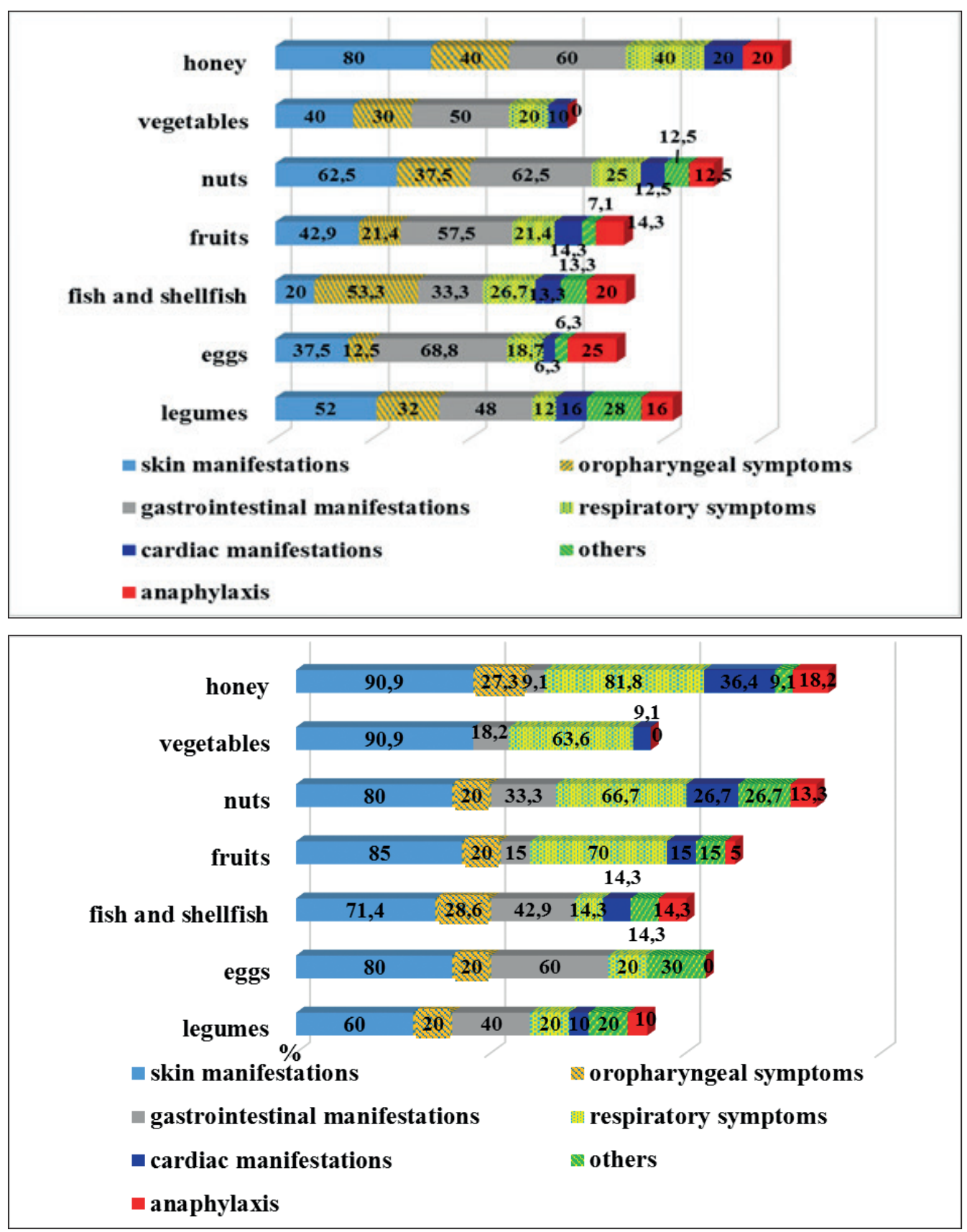

Fig. 1. Comparative evaluation of clinical manifestations depending on the leading significant food allergen in the group of children with gastroduodenal pathology verse allergic reactions to food does not always confirm the allergic genesis of food intolerance and may be due to the pathology of the digestive tract. Therefore, during the analysis of the nutritional history in the examined children, special attention was paid to the peculiarities of the course of clinical symptoms after consumption of suspected products. As the results of our study show, the range of clinical manifestations in the examined children varied depending on the sensitizing component and was characterized by polymorphic lesions of various organs and systems. The most were common skin manifestations (redness, itching, urticaria, angioneurotic edema, eczema, skin irritation), as well as oropharyngeal symptoms (itching, swelling of lips, tongue, pharynx), voice change (laryngeal edema), difficulty breathing), gastrointestinal tract (abdominal pain, nausea, vomiting, diarrhea, blood in the stool, belching, difficulty swallowing). Meanwhile, the symptoms of upper and lower respiratory tract (itchy nose, sneezing, runny nose, catarrhal discharge with conjunctivitis or without it, cough, heaviness in the chest, wheezing, shortness of breath, breathlessness, cardiovascular system (dizziness, hypotension, tachycardia, hypotension) and other conditions (paleness, fatigue, growth retardation, crying / screaming, malnutrition, etc.) were met less frequently and were characterized by certain differences in the observation groups. Allergic symptoms in most patients were moderate, but there were isolated cases of anaphylactic reactions that required immediate care.

Among the studied groups (Fig. 1 and Fig. 2) the most common clinical symptom of allergic reactions when eating legumes (especially peanuts) were manifestations of the skin and mucous membranes, which is similar to the data 
from American researchers [3, 4]. Thus, the development of these symptoms was characteristic for $84 \%$ of the examined group 1, of which $52 \%$ of patients had skin symptoms and $32 \%$ had manifestations of the oropharynx, which were mainly accompanied by itching and sore throat, and had no significant differences among children of the comparison groups. In isolated cases, the initial manifestations of laryngeal edema were observed, which led to difficulty breathing in $16 \%$ of children with gastroduodenal pathology against $10 \%$ of patients with atopic dermatitis. However, as the results of our study show, the frequency of anaphylactic reactions was significantly lower as compared to Western countries $(23.7-34.9 \%)[3,5,6]$.

In childhood, food allergy to eggs remains quite difficult to diagnose, because a large number of food products contain this product as one of the main components. The severity of the reaction is unpredictable, therefore, clinical manifestations can range from mild and moderate to more severe and even anaphylactic. The results of our research show that children with gastroduodenal pathology after consumption of these products most often had gastrointestinal symptoms (68.8\%). When eating fish and seafood, every second (53.3\%) patient in Group 1 developed oropharyngeal symptoms and every third patient (33.3\%) had gastrointestinal symptoms that were manifested as abdominal pain and dyspeptic syndromes. At the same time, the children of the second group were characterized by a predominance of skin alterations, manifested by dryness, itching and irritation.

A characteristic feature of children in the second group was the predominance of skin manifestations and symptoms of the upper and lower respiratory tract. The frequency of respiratory manifestations was high in the consumption of honey (81.8\%), fruits (70\%), nuts (66.7\%) and vegetables (63.6\%). Thus, we can draw the conclusion about the versatility and nonspecificity of food allergy symptoms, which vary depending on the etiologically significant allergen. Hence, the peculiarities of the clinical course in food consumption by children of Group 1 consisted in the predominance of gastrointestinal symptoms and manifestations of the skin and mucous membranes (oropharynx), whereas children of the second group were characterized by a high frequency of respiratory manifestations, which has an unfavorable prognosis regarding further risk of bronchial asthma development.

A retrospective analysis of patients of Group 1 with allergy to cow's milk proteins revealed that in more than half of the examined subjects (73.5\%), the development of allergic reactions to dairy products was formed by the delayed-type mechanism (from 1 to 12 hours), which can be an evidence of mixed (IgE-independent and cell-mediated) reactions. In such cases, it is difficult to trace the relationship of symptoms with food and identify the significant allergen. Therefore, such patients are often observed by gastroenterologists under the guise of non-allergic gastrointestinal diseases. The development of allergic reactions of the immediate type (from the moment of consumption to 1 hour) was observed in 15 (60\%) when eating legumes (especially peanuts) and in $12(80 \%)$ patients with gastroduodenal pathology when eating fish and seafood, which required careful monitoring of the health of such children to prevent the development of anaphylaxis. Among those examined with atopic dermatitis, the immediate type of allergic reactions was observed in $11(73.4 \%)$ children when eating nuts, in 17 (85\%) when eating fruit and in $6(54.6 \%)$ - when eating vegetables and in some patients it was accompanied by the formation of the oral-allergic syndrome. In turn, this may be due to the development of cross-reactivity, which is based on the primary sensitization of the body to homologous inhalation allergens, as a result of which food allergens of plant origin can cause clinical symptoms of food allergy. That is why such cases require a differentiated and personalized approach to each patient.

It is known that even a small amount of allergenic protein can provoke the development of adverse allergic reactions when eating the product, which confirms the role of immunologically mediated mechanisms. Therefore, the assessment of dose-dependence with minimal exposure to the consumed allergen is of great clinical importance for the verification of true allergic reactions to food. Thus, the study found that on average in every 5th child of Group 1 , the development of allergic reactions after a few bites of the product occurred when eating legumes $(20 \%)$ and fish (20\%), and in every 4 th - when eating eggs (25\%). The proportion of children who developed allergic reactions after long-term (several days) consumption of the product was higher among patients with gastroduodenal pathology as compared with children in Group 2.

The development of allergic reactions with repeated consumption of the same product was constant in half of children with hypersensitivity to fish (46.7\%) and dairy products $(55.9 \%)$, in a third - with allergies to peanuts (32\%) and in every fourth child with an allergic reaction to eggs (25\%). The constant development of skin allergic symptoms in the subjects of Group 2 was observed after taking nuts in $9(60 \%)$ of 15 children with hypersensitivity to this ingredient and in every third patient when eating fruits (30\%), vegetables (27.3\%) and honey (27.3\%).

The leading place in the regulation of immunopathological mechanisms of allergic reactions belongs to cytokines. The fact remains that the activation of T-helpers (Th2) in the formation of Th2 lymphocytes with an increased synthesis of their corresponding cytokines (interleukins-4, 5,13 ) plays a leading role in the immunopathogenesis of allergies $[7,8]$. The starting point for the development of allergic inflammation is the triggering of pro-inflammatory effects, such as regulation of adhesion molecule expression, increased vascular wall permeability, mucus hyperproduction and modulation of cell transport due to enhanced chemokine production, which in turn leads to the active involvement of eosinophils in target organs. The main inducers of allergies are IL-4 and IL-13. Today, the role of these cytokines in the development of allergic reactions is well known, but the importance of cytokines and some chemokines in the formation of specific clinical phenotypes of allergic diseases in childhood needs further 
Table 2. Estimated result of the analysis of immunological profile indicators in the examined children $(M \pm m), \mathrm{pg} / \mathrm{ml}$

\begin{tabular}{cccc}
\hline & & Observation groups & \\
\cline { 2 - 4 } Immunological markers & $\begin{array}{c}\text { Group 1 } \\
\text { Children with gastroduodenal } \\
\text { pathology }(\mathbf{n = 3 4 )}\end{array}$ & $\begin{array}{c}\text { Group 2 } \\
\text { Children with atopic } \\
\text { dermatitis (n=30) }\end{array}$ & $\begin{array}{c}\text { Apparently healthy } \\
\text { children (control group) } \\
\text { (n=22) }\end{array}$ \\
\hline IL-4 & $0.22 \pm 0.05^{* * *}$ & $0.34 \pm 0.07^{* * *}$ & $0.009 \pm 0.006$ \\
\hline IL-10 & $4.3 \pm 0.6^{*}$ & $3.9 \pm 0.4^{* *}$ & $8.3 \pm 1.5$ \\
\hline TARC/CCL-17 & $116.6 \pm 16.7^{* * *}$ & $141.5 \pm 18.7^{* * *}$ & $11.5 \pm 3.7$ \\
\hline
\end{tabular}

Note. ${ }^{*}$ - the significance of the difference as compared with the control group $(\mathrm{p}<0.05)$;

$*^{* *}-(p<0.01) ;^{* * *}-(p<0.001)$

study. Since data on the prevalence of food allergies are based solely on self-assessment are not reliably significant [1], and the immune mechanisms of food allergy need to be clarified, we studied the cytokine profile (IgE, IL-4 and IL-10) using the chemokine TARC/CCL-17 to assess the immunological changes in children.

The study of the immunological status of patients in comparison with the control group revealed significant increases in pro-inflammatory Th2-cytokines - interleukin- 4 and chemokine TARC/CCL-17 and a simultaneous decrease in anti-inflammatory interleukin-10 in children of the 1st and 2nd groups who had gastrointestinal and skin manifestations of allergic reactions when eating food products. Although no significant differences between the levels of immunological markers of the 1 st and 2nd groups were found, there was a tendency to their prevalence in the group of children with atopic dermatitis. The study of the cytokine profile in patients demonstrates the leading role of the $\mathrm{Th} 2$ immune response in the development of allergic reactions to food in the examined patients.

The average level of IL- 4 in the serum of children with gastroduodenal pathology was significantly higher than the control values $(\mathrm{p}<0.001)$ and averaged $0.22 \pm 0.05 \mathrm{pg} / \mathrm{ml}$ against $0.009 \pm 0.006 \mathrm{pg} / \mathrm{ml}$, respectively. At the same time, the average level of IL- 4 in Group 1 was by 1.5 times lower than in children with atopic dermatitis.

Statistically significant reduced levels of IL-10 in Group $1(4.3 \pm 0.6)$ and in Group $2(3.9 \pm 0.4)$ as compared with the group of apparently healthy children may reflect a tendency to persistent / chronic inflammation.

Thymus- and activation-regulated chemokine - TARC/ CCL-17 is a ligand of a specific chemokine receptor CCR4, which promotes the targeted migration of Th2 cells that provide a humoral immune response to antigens, including those of an allergic nature. This chemokine has been intensively studied in Japan since 2008, and as of 2020, it is included in the Japanese recommendations [9] as a biomarker for the diagnosis and assessment of the severity of patients with atopic dermatitis. Its role in the development of allergic diseases such as allergic rhinitis and bronchial asthma has been proven in scientific works. In addition, this cytokine was a useful parameter for differentiating atopic dermatitis from skin diseases of non-allergic nature, namely psoriasis. As shown by the results of our study, the level of TARC/CCL17 (mean value $116.6 \pm 16.7 \mathrm{pg} / \mathrm{ml}$ ) in children with gastroduodenal pathology significantly exceeded that of children in the control group. It should be noted that almost half (47.1\%) of the examined chemokine levels were registered within $\geq 100 \mathrm{pg} / \mathrm{ml}$, but in the group of children with atopic dermatitis, the proportion of children with TARC/CCL17 $\geq 100 \mathrm{pg} / \mathrm{ml}$ was higher (63.3\%).

A reliable increase in the level of chemokine TARC/ CCL17 ( $p=0.001)$ in our study in children with atopic dermatitis confirms the diagnostic value of this cytokine in the mechanisms of regulation of immunopathological conditions associated with allergies and is comparable with the data of other authors [J. Nakazato, M. Kishida, 2008; H. Esaki, S. Takeuchi, 2016]. Therefore, as shown by the results of our study, high levels of TARC/CCL17 can be used as a diagnostic marker of the gastrointestinal form of food allergy. Thus, unidirectional immunological changes indicate an imbalance of the immune response due to the prevalence of pro-inflammatory IL-4 and TARC/CCL17 and reduced anti-inflammatory IL-10 in the examined children of Groups 1 and 2, which is determined by their active participation in the implementation of allergic inflammation.

\section{CONCLUSIONS}

The study of the features of adverse reactions to food in school-age children identified specific clinical criteria for food allergies: structure, dose dependence, frequency and rate of allergic reactions after consumption of food products, depending on the skin or gastrointestinal manifestations.

The immunological status of the examined children was characterized by a significant increase in the levels of pro-inflammatory cytokines interleukin-4, chemokine TARC/CCL-17 and a decrease in anti-inflammatory interleukin-10, which confirms the importance of these markers in the mechanisms of regulation of immunopathological conditions associated with food allergies. The identified data substantiate the prospects for the introduction of these markers in the diagnostic protocols at different stages of medical care.

\section{REFERENCES}

1. Loh W., Tang M. The epidemiology of food allergy in the global context. Int J Environ Res Public Health. 2018;15(9):2043. 
2. Prescott S., Allen K.J. Food allergy: Riding the second wave of the allergy epidemic. Pediatr. Allergy Immunol. 2011;22:155-160. doi: 10.1111/j.1399-3038.2011.01145.x.

3. Leickly F.E., Kloepfer K.M., Slaven J.E., Vitalpur G. Peanut allergy: an epidemiologic analysis of a large database.J Pediatr. 2018;192:223-8.e1.

4. Al-Muhsen S., Clarke A.E., Kagan R.S. Peanut allergy: an overview. CMAJ. 2003;168:1279-1285.

5. Yang L., Clements S., Joks R. A retrospective study of peanut and tree nut allergy: Sensitization and correlations with clinical manifestations. Allergy Rhinol (Providence) 2015;6:39-43.

6. Lee M.P., SaffariS.E., LohW. et al. A5-year retrospective review of children with peanut allergy in the largest paediatric hospital in Singapore. Asia Pac Allergy. 2020;10(1):e6. doi:10.5415/apallergy.2020.10.e6.

7. Kryuchko T.0., Kaidashev I.P., Vovk Yu.0. Henetychnyi polimorfizm Tollpodibnoho retseptora 4 u ditei khvorykh na atopichnu bronkhialnu [Genetic polymorphism of Toll-like receptor 4 in children with atopic bronchial asthma]. Klinichna imunolohiia. Alerholohiia. Infektolohiia 2011; 5: 52-54.

8. Garra A., Vieira P. Regulatory T-cells and mechanisms of immune system control. Nature Med 2004; 10: 801-805.

9. Katoh N., Ohya Y., Ikeda M. et al. Japanese guidelines for atopic dermatitis 2020. Allergology International 2020; 69: 356-369. doi:10.1016/j.alit.2020.02.006.

The present article is a part of the research project of Ukrainian Medical Stomatological Academy «The study of pathogenetic mechanisms of the most widespread diseases of infancy, optimization of their diagnostics and treatment». Completion period: 2017-2021 (Number of state registration 0117.U004683).

\section{ORCID and contributionship:}

Tetyana O. Kryuchko: 0000-0002-5034-4181 A,E,F

Liudmyla M. Bubyr: 0000-0001-9736-3593 B,C,D,F

Inna M. Nesina: 0000-0003-1514-2434 ${ }^{B, D, F}$

Olha Y. Tkachenko: 0000-0002-9976-6430 B,C,F

Olga V. Izmailova: 0000-0003-4770-3494 ${ }^{E, F}$

Olha A. Poda: 0000-0002-2314-8628 B,E

Viktoriia V. Shcherbak: 0000-0002-9268-6454 ${ }^{B, E}$

\section{Conflict of interest:}

The Authors declare no conflict of interest

\section{CORRESPONDING AUTHOR}

\section{Liudmyla M. Bubyr}

23 Shevchenka Str., 36011, Poltava, Ukraine. tel: +380532-606-491; +38099-795-55-74

e-mail: Iyudmila.bubyr@ukr.net

Received: 02.07 .2020

Accepted: 03.09.2020

A - Work concept and design, B - Data collection and analysis, C - Responsibility for statistical analysis, D-Writing the article, $\mathbf{E}$-Critical review, $\mathbf{F}$ - Final approval of the article 